\title{
Hydrothermal Synthesis and Properties of Diluted Magnetic Semiconductor $\mathrm{Zn}_{1-\mathrm{x}} \mathbf{M n}_{\mathrm{x}} \mathrm{O}$ Nanowires
}

\author{
X. Y. Zhang ${ }^{*}$, J. Y. Dai ${ }^{2}$, H. C. Ong ${ }^{3}$ \\ ${ }^{1}$ Department of Chemical Engineering, Monash University, Melbourne, Australia \\ ${ }^{2}$ Department of Applied Physics, Hong Kong Polytechnic University, Kowloon, Hong Kong, China \\ ${ }^{3}$ Department of Physics, Chinese University of Hong Kong, Shatin, Hong Kong, China \\ E-mail: xinyi.zhang@monash.edu.au \\ Received April $7^{\text {th }}$, 2011; revised April 28 $8^{\text {th }}, 2011$; accepted May $11^{\text {th }}, 2011$.
}

\begin{abstract}
We report the synthesis of oriented single crystalline $\mathrm{Mn}$ doped $\mathrm{ZnO}$ nanowires through a hydrothermal method. Structural characterizations using X-ray diffraction and transmission electron microscopy revealed that the Mn was doped into the lattice structure, forming solid solution. The Mn doped $\mathrm{ZnO}$ nanowires possess wurtzite structure with a c-axis growth orientation. The physical properties of the nanowires were investigated. Mn doped $\mathrm{ZnO}$ nanowires were found to be ferromagnetic with Curie temperature of about $30 \mathrm{~K}$. A deep level emission band at about $566 \mathrm{~nm}$ was observed at room temperature.
\end{abstract}

Keywords: Semiconductors, Nanowire, Crystal Growth, Electron Microscopy, Curie Temperature, Photoluminescence

\section{Introduction}

One-dimensional nanostructures have attracted a great deal of interest not only because of their basic scientific richness, but also of their potential utilization in optical and electronic devices [1-6]. $\mathrm{ZnO}$ is one of the most important semiconductors due to its wide direct band gap $(3.37 \mathrm{eV})$ and large exciton binding energy $(60 \mathrm{meV})$. To date, $\mathrm{ZnO}$ in bulk and thin film format has been widely used in field emission display, solar cell, chemical sensors, and other devices [7-9]. Recently, dilute magnetic semiconductors (DMSs) have attracted a great deal of attention in the past few years as enabling materials in the emerging field of "spintronics". DMSs are semiconductor solid solutions, where a small percentage of cations are replaced by magnetic impurities such as Mn. Unusual magnetotransport and magnetooptical phenomena like large Faraday rotations, giant negative magnetoresistances, and magnetic field induced metalinsulator transitions have been observed. Among the DMSs, Mn- doped II-VI compounds have been extensively studied. However, most of the II-VI compounds studied are chalcogenides; the corresponding oxides are comparatively less investigated. Theoretical calculations predict that $\mathrm{ZnO}$ should exhibit ferromagnetism above room temperature on doping with Mn [10,11]. This prediction has initiated in- creasing efforts on $\mathrm{Mn}$ doping of $\mathrm{ZnO}$ nanostructures. Diluted magnetic semiconductor (DMS) behavior has been observed in many transition-metal doped $\mathrm{ZnO}$ films [12-14], and Curie temperatures above room temperature were achieved $[15,16]$. Although the efforts aimed at understanding the origin of the ferromagnetism resulted in hundreds of papers, substantial debate still remains. The available data cannot further advance our understanding of the mechanism since the data obtained so far on $\mathrm{Mn}$ doped $\mathrm{ZnO}$ are not quite consistent, for example, besides the ferromagnetic behavior, behavior of spin glass [17] and paramagnet [18] have also been observed. Therefore, more detailed works are essential to understand the behavior of these materials. $\mathrm{Mn}$ doped $\mathrm{ZnO}$ nanowires (or nanobelts) have been obtained by doping $\mathrm{Mn}$ into $\mathrm{ZnO}$ by using various techniques, such as ion implantation [19], thermal evaporation [20-23]. These methods generally require high temperature and expensive equipments. On the other hand, wet chemical method has been proven to be a simple and versatile approach for preparing $\mathrm{ZnO}$ nanowires or nanorods due to its relatively low growth temperature and good potential for mass production [2427]. However, to the best of our knowledge, there is no report on the synthesis of $\mathrm{Mn}$ doped $\mathrm{ZnO}$ nanowires by using wet chemical method. Here, we report a simple hydrothermal method to prepare the $\mathrm{Mn}$ doped $\mathrm{ZnO}$ 
nanowires. The structure and light-emitting properties are also investigated.

\section{Experimental Section}

Materials. Zinc sulfate hydrate $\left(\mathrm{ZnSO}_{4} \cdot 7 \mathrm{H}_{2} \mathrm{O}\right)$, manganese sulfate hydrate $\left(\mathrm{MnSO}_{4} \cdot \mathrm{H}_{2} \mathrm{O}\right)$, carbamide $\left(\mathrm{CON}_{2} \mathrm{H}_{4}\right)$, sodium hydroxide $(\mathrm{NaOH})$, and ethanol were of analytical grade and used without further purification. Double-distilled water was employed for all experiments.

Synthesis. In a typical synthesis of $\mathrm{Mn}$ dopped $\mathrm{ZnO}$ nanowires, a solution of $50 \mathrm{ml} 0.1 \mathrm{M} \mathrm{ZnSO}_{4}, 3 \mathrm{ml} 0.1 \mathrm{M}$ $\mathrm{MnSO}_{4}, 15 \mathrm{ml} 1 \mathrm{M}$ carbamide $\left(\mathrm{CON}_{2} \mathrm{H}_{4}\right)$ and $10 \mathrm{ml}$ $\mathrm{C}_{2} \mathrm{H}_{5} \mathrm{OH}$ was placed in a sealed Teflon autoclave with the $\mathrm{pH}$ of the solution adjusted to 14 by $\mathrm{NaOH}$. The solution was then heated at $180^{\circ} \mathrm{C}$ for 12 hours and the resulting products were obtained by washing and drying the yellowish precipitates at $60^{\circ} \mathrm{C}$ for 12 hours.

Characterization. The microstructure and composition of the nanowires were investigated using an X-ray diffractometer (XRD, PW1140/90) with $\mathrm{Cu} \mathrm{K \alpha}$ radiation (25 $\mathrm{mA}$ and $40 \mathrm{kV}$ ), a scanning electron microscope (SEM, JEOL JSM-6300), transmission electron microscope (TEM, JEOL-2010), energy dispersive spectroscopy (EDS), and electron energy-loss spectroscopy (EELS). Quantitative EDS analysis shows the molar ratio of $\mathrm{Mn}$ is around $3 \%$. The magnetic properties of the nanowires were studied using a Superconducting Quantum Interference Device (SQUID) magnetometer (MPMS$5 \mathrm{~S}$ ). The photoluminescence (PL) measurements were performed by using a Kimmon $\mathrm{HeCd}$ laser $(325 \mathrm{~nm}, 55$ $\mathrm{mW}$ ) in a closed cycle Oxford cryostat. The optical signal was dispersed by a $0.25 \mathrm{~m}$ Oriel spectrometer and captured by an Andor CCD detector.

\section{Results and Discussion}

Figure 1 shows the XRD spectrum of the $\mathrm{Zn}_{1-\mathrm{x}} \mathrm{Mn}_{\mathrm{x}} \mathrm{O}$ nanowires, the reflection peaks of hexagonal structured $\mathrm{ZnO}$ are distinguishable, revealing that the doping of $\mathrm{Mn}$ does not change the wurtzite structure of $\mathrm{ZnO}$. No Mnrelated impurity phases were observed. Figure 2 (a) and (b) show the typical SEM and TEM images of the $\mathrm{Zn}_{1-\mathrm{x}} \mathrm{Mn}_{\mathrm{x}} \mathrm{O}$ nanowires, respectively. The nanowires have uniform diameters along their entire length, the diameters and lengths are in the range of 10 to $100 \mathrm{~nm}$ and 2 to $10 \mu \mathrm{m}$, respectively. Figure 3(a) shows TEM image of a typical long $\mathrm{Zn}_{1-\mathrm{x}} \mathrm{Mn}_{\mathrm{x}} \mathrm{O}$ nanowire, the right inset shows the selected-area electron diffraction (SAED) pattern taken from a single nanowire, the analysis of the SAED reveals that the $\mathrm{Zn}_{1-\mathrm{x}} \mathrm{Mn}_{\mathrm{x}} \mathrm{O}$ nanowire is single crystalline and grows along the [0001] orientation. The presence of $\mathrm{Mn}$ in the lattice was confirmed by the EELS measurement, the spectrum shows that $\mathrm{Zn}$ and Mn coexist along with $\mathrm{O}$ (Figure 3(b)). The Mn-L3/L2 intensity ratio indicates one electron in the d-orbital suggesting $\mathrm{Mn}$ to be in the +2 oxidation state. The nature of single-crystal structure of the $\mathrm{Zn}_{1-\mathrm{x}} \mathrm{Mn}_{\mathrm{x}} \mathrm{O}$ nanowires and the growth orientation were further confirmed by high-resolution TEM (HRTEM) image as shown in Figure 4. The HRTEM images analysis shows that the $\mathrm{Zn}_{1-\mathrm{x}} \mathrm{Mn}_{\mathrm{x}} \mathrm{O}$ nanowires are structurally uniform without any signify-

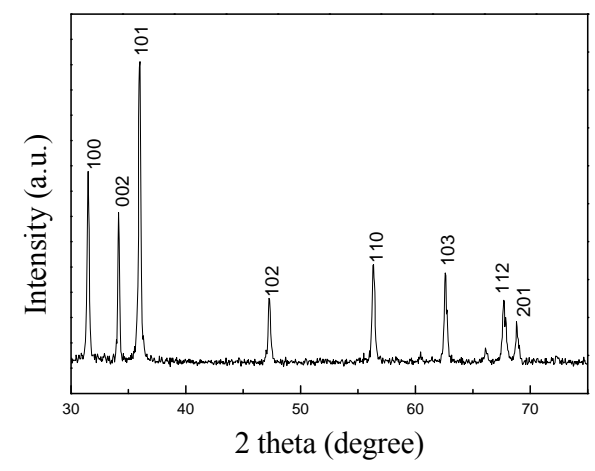

Figure 1. The XRD spectrum of the $\mathrm{Zn}_{1-\mathrm{x}} \mathrm{Mn}_{\mathrm{x}} \mathrm{O}$ nanowires.

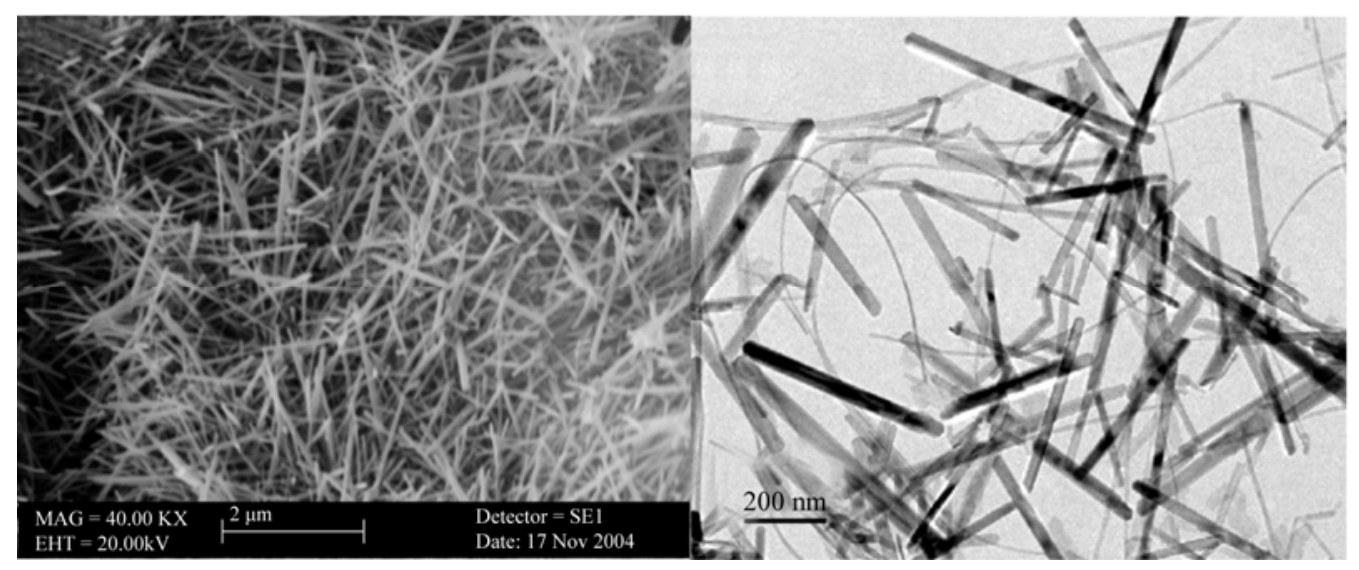

Figure 2. (a) SEM; (b) TEM images of $\mathrm{Zn}_{1-\mathrm{x}} \mathrm{Mn}_{\mathrm{x}} \mathrm{O}$ nanowires. 


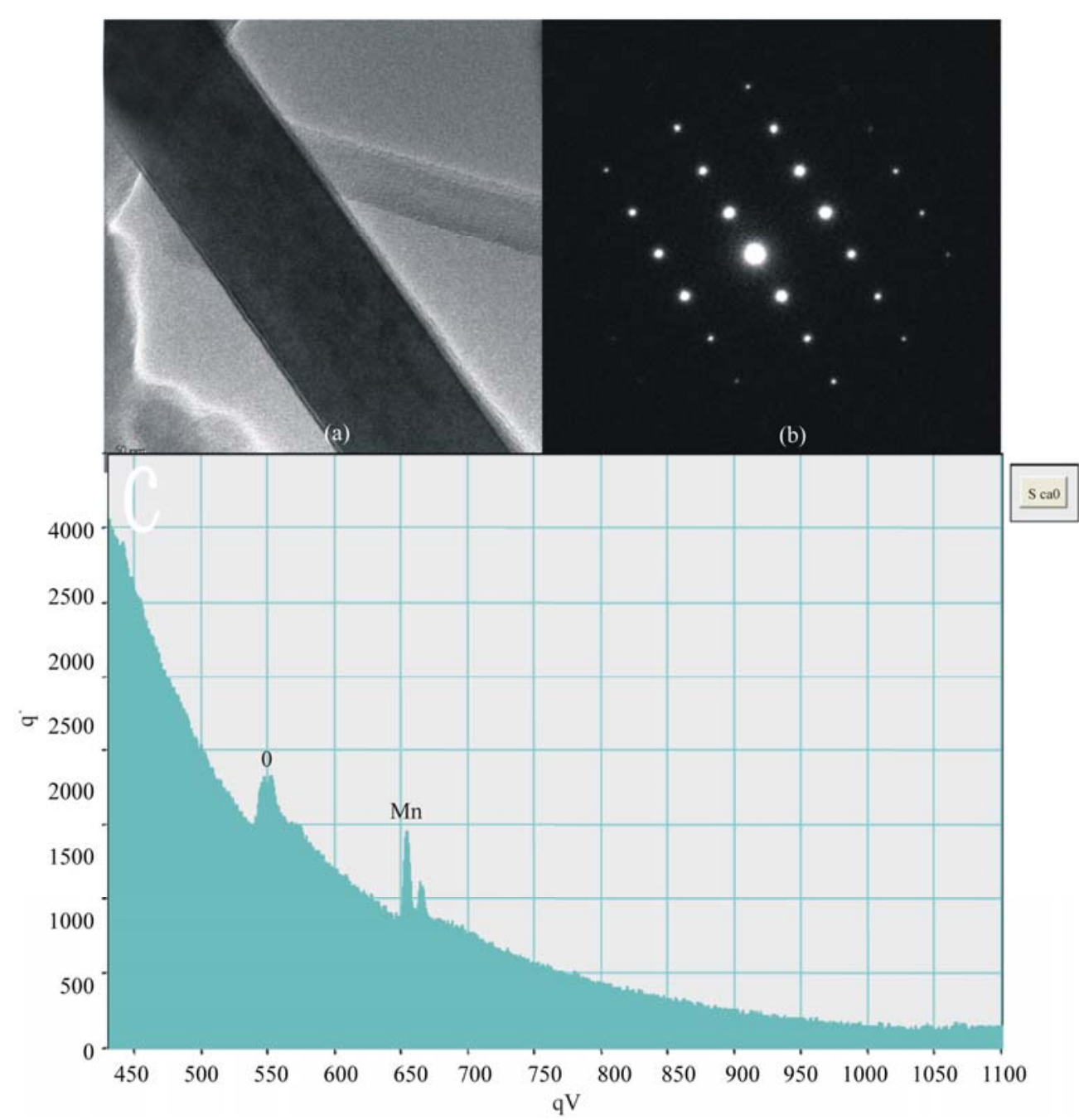

Figure 3. (a) TEM image of a $\mathrm{Zn}_{1-\mathrm{x}} \mathrm{Mn}_{\mathrm{x}} \mathrm{O}$ nanowire; (b) the corresponding electron diffraction pattern of the $\mathrm{Zn}_{1-\mathrm{x}} \mathrm{Mn} \mathrm{n}_{\mathrm{x}} \mathrm{O}$ nanowire; (c) the corresponding electron energy loss spectroscopy spectrum of the $\mathrm{Zn}_{1-\mathrm{x}} \mathrm{Mn}_{\mathrm{x}} \mathrm{O}$ nanowire.

cant defect. These characteristics of the $\mathrm{Zn}_{1-\mathrm{x}} \mathrm{Mn}_{\mathrm{x}} \mathrm{O}$ nanowires are similar to those $\mathrm{ZnO}$ nanowires synthesized by hydrothermal methods.

The magnetic properties of the as-prepared $\mathrm{Zn}_{1-\mathrm{x}} \mathrm{Mn}_{\mathrm{x}} \mathrm{O}$ nanowires were investigated using a SQUID magnetometer. Figure 5 shows the temperature dependence of the magnetization (M-T) during cooling in a magnetic field of $5 \mathrm{~T}$, the magnetization shows a slight increase from 100 to $40 \mathrm{~K}$, followed by a steep increase below $30 \mathrm{~K}$ until $5 \mathrm{~K}$. It can be seen that the FC curve shows a sharp increase at low temperature, this behavior has been considered as the effect of randomness and disorder on percolating FM clusters in most diluted magnetic semiconductor materials. So the Curie temperature of $\mathrm{Zn}_{1-\mathrm{x}} \mathrm{Mn}_{\mathrm{x}} \mathrm{O}$ nanowires is about $30 \mathrm{~K}$, which is higher than $25 \mathrm{~K}$ and lower than $50 \mathrm{~K}$, observed for $\mathrm{ZnMnO}$ thin film and $\mathrm{Mn}$ doped $\mathrm{ZnO}$ nanotetrapods, respectively $[28,29]$. It seems that data reported so far on $\mathrm{Mn}$ doped $\mathrm{ZnO}$ are not quite consistent. These discrepan- cies may be due to the different fabrication methods. Obviously, more detailed works are essential to understand the magnetic behaviors of these materials.

The photoluminescence (PL) of the $\mathrm{Zn}_{1-\mathrm{x}} \mathrm{Mn}_{\mathrm{x}} \mathrm{O}$ nanowires and undoped $\mathrm{ZnO}$ nanowires was investigated at room temperature. Usually, the PL spectrum of the undoped $\mathrm{ZnO}$ nanowires shows characteristic UV emission and broad green emission, in agreement with previously reported results for $\mathrm{ZnO}$ nanowires [30]. However, the photoluminescence of the $\mathrm{Zn}_{1-\mathrm{x}} \mathrm{Mn}_{\mathrm{x}} \mathrm{O}$ nanowires is apparently different from that of undoped $\mathrm{ZnO}$ nanowires. It can be observed from Figure 6 that a strong green emission appears, while the violet emission completely disappears. The mechanism of green emission has been suggested to be mainly due to the existence of various points that can easily form recombination centers [31]. In the present situation, the strong green emission suggests that these $\mathrm{Zn}_{1-\mathrm{x}} \mathrm{Mn}_{\mathrm{x}} \mathrm{O}$ nanowires should have many point 


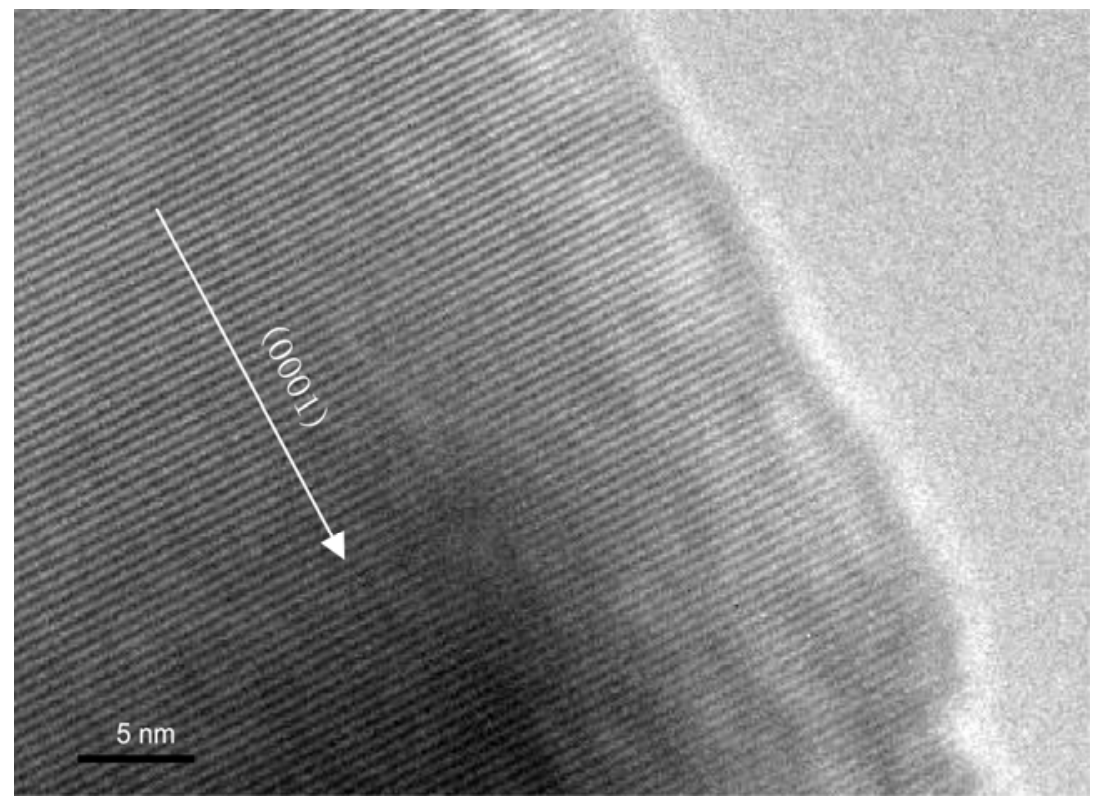

Figure 4. HRTEM image of a $\mathrm{Zn}_{1-\mathrm{x}} \mathrm{Mn}_{\mathrm{x}} \mathrm{O}$ nanowire.

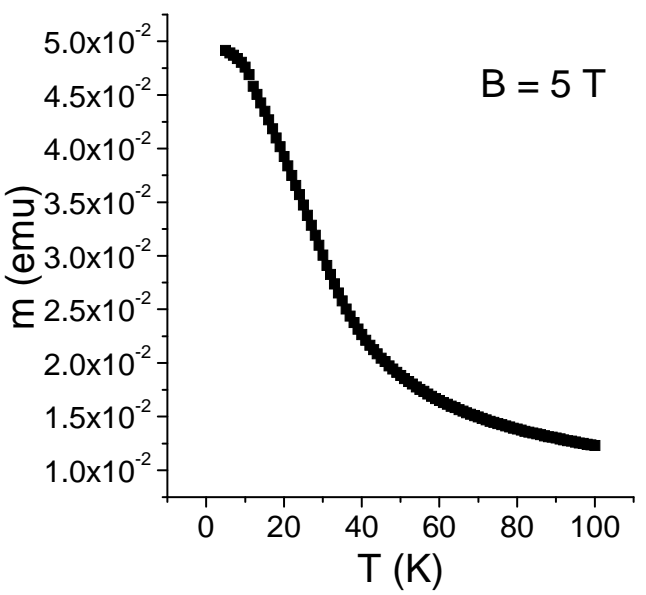

Figure 5. Temperature dependent magnification (M-T) curve of the $\mathrm{Zn}_{1-\mathrm{x}} \mathrm{Mn}_{\mathrm{x}} \mathrm{O}$ nanowires at a magnetic field $\mathrm{B}=5 \mathrm{~T}$.

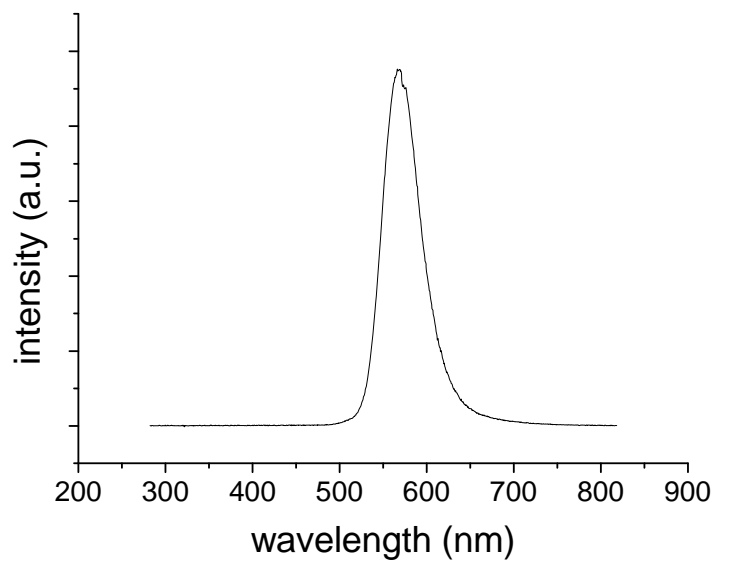

Figure 6. The photoluminescence (PL) spectrum recorded from the $\mathrm{Zn}_{1-\mathrm{x}} \mathrm{Mn}_{\mathrm{x}} \mathrm{O}$ nanowires at room temperature. defects, such as oxygen vacancies $\mathrm{V}_{\mathrm{O}}^{+}$[32,33]. It can be inferred that the $\mathrm{ZnO}$ formed during the hydrothermal process features a high density of oxygen vacancies, which enhanced the green emission intensity. It has been suggested that the violet emission band could be assigned to the $\mathrm{V}_{\mathrm{Zn}}{ }^{-}$centers, and the violet emission intensity depends on the density of $\mathrm{V}_{\mathrm{Zn}}^{-}$. The high density of $\mathrm{V}_{\mathrm{O}}^{+}$resulted during the hydrothermal process can lead to a decrease in the density of $\mathrm{V}_{\mathrm{Zn}}^{-}$centers and a increase of nonradiative recombination processes. Furthermore, the doping of $\mathrm{Mn}$ in the $\mathrm{ZnO}$ may change the electronic structure of $\mathrm{ZnO}$ such as the position of the Fermi level [34]. These should be responsible for the quench of the violet emission.

\section{Conclusions}

In conclusion, large quantity and single crystalline $\mathrm{Zn}_{1-\mathrm{x}} \mathrm{Mn}_{\mathrm{x}} \mathrm{O}$ nanowires have been synthesized through a hydrothermal method. Structural characterization by $\mathrm{x}$-ray diffraction and transmission electron microscopy revealed that the $\mathrm{Zn}_{1-\mathrm{x}} \mathrm{Mn}_{\mathrm{x}} \mathrm{O}$ nanowires possess wurtzite structure with c-axis growth orientation. Mn doped $\mathrm{ZnO}$ nanowires are ferromagnetic with Curie temperature $\sim 30$ $\mathrm{K}$. The $\mathrm{Zn}_{1-\mathrm{x}} \mathrm{Mn}_{\mathrm{x}} \mathrm{O}$ nanowires exhibit a deep level emission at $566 \mathrm{~nm}$. This simple approach shows promise for fabricating nanoscale sensor and other devices.

\section{Acknowledgments}

This work was funded by the Australian Research Council and Monash University. One of the authors (X. Zhang) 
thanks the Australian Research Council for the Australian Research Fellowship.

\section{References}

[1] S. Iijima, Nature Vol. 354, No. 6348, 1991, pp. 56-58.

[2] M. H. Devoret, D. Esteve, and C. Urbina, Nature Vol. 360, No. 6404, 1992, pp. 547-553.

[3] H. J. Dai, E. W. Wong, Y. Z. Lu, S. Fan, and C. M. Lieber, Nature Vol. 375, No. 6534, 1995, pp. 769-772.

[4] A. P. Alivisatos, Science Vol. 271, No. 5251, 1996, pp. 933-937.

[5] M. H. Huang, S. Mao, H. Feick, H. Yan, Y. Wu, H. Kind, E. Weber, R. Russo, and P. Yang, Science Vol. 292, 2001, pp. 1897-1899.

[6] A. M. Morales and C. M. Lieber, Science Vol. 279, No. 5348, 1998, pp. 208-211.

[7] N. Wang, Y. F. Zhang, Y. H. Tang, C. S. Lee, and S. T. Lee, Appl. Phys. Lett. Vol. 73, No. 26, 1998, pp. 3902- 3904.

[8] D. C. Look, Mater. Sci. Eng. B Vol. 80, No. 1-3, 2001, pp. 383-387.

[9] Z. K. Tang, G. K. L. Wong, P. Yu, M. Kawasaki, A. Ohtomo, H. Koinuma, and Y. Segawa, Appl. Phys. Lett. Vol. 72, No. 25, 1998, pp. 3270-3272.

[10] T. Dietl, H. Ohno, F. Matsukura, J. Cibert, and D. ferrand, Science Vol. 287, No. 5455, 2000, pp. 1019-1022.

[11] T. Dietl, Semicond. Sci. Technol. Vol. 17, No. 4, 2002, pp. 377.

[12] Y. W. Heo, M. P. Lvill, K. Ip, D. P. Norton, S. J. Pearton, J. G. Kelly, R. Rairigh, A. F. Hebard, and T. Steiner, Appl.

Phys. Lett. Vol. 84, No.13, 2004, pp. 2292-2294.

[13] W. Prellier, A. Foucheta, and B. Mercey, J. Phys. C Vol. 15, No. 37, 2003, pp. R1583-R1601.

[14] S. J. Han, J. W. Song, C. H. Yang, S. H. Park, Y. H. Jeong, and K. W. Rhie, Appl. Phys. Lett. Vol. 81, No. 22, 2002, pp. 2412-2414.

[15] P. Sharma, A. Gupta, K. V. Rao, F. J. Owens, R. Sharma, R. Ahuja, J. M. O. Guillen, B. Johansson, and G. A. Gehring, Nature Mater. Vol. 2, 2003, pp. 673-677.

[16] D. P. Norton, S. J. Pearton, A. F. Hebard, N. Theodoropoulou, L. A. Boatner, and R. G. Wilson, Appl. Phys. Lett. Vol. 82, No. 26, 2003, pp. 239-241.
[17] T. Fukumura, Z. Jin, M. Kawasaki, T. Shono, T. Hasegawa, and H. Koinuma, Appl. Phys. Lett. Vol. 78, No. 7, 2001, pp. 958-960.

[18] X. M. Cheng, and C. L. Chien, J. Appl. Phys. Vol. 93, No. 10, 2003, pp. 7876-7878.

[19] C. Ronning, P. X. Gao, Y. Ding, Z. L. Wang, and D. Schwen, Appl. Phys. Lett. Vol. 84, No. 5, 2004, pp. 783-785.

[20] M. H. Huang, Y. W. Henning Feick, N. Tran, E. Weber, and P. Yang, Adv. Mater. Vol. 13, No. 2, 2001, pp. 113-116.

[21] Z. R. Dai, Z. W. Pan, and Z. L. Wang, Adv. Funct. Mater. Vol. 13, No. 1, 2003, pp. 9-24.

[22] V. A. L. Roy, A. B. Djurišić, H. Liu, X. X. Zhang, Y. H. Leung, M. H. Xie, J. Gao, H. F. Lui, and C. Surya, Appl. Phys. Lett. Vol. 84, No. 5, 2004, pp. 756-758.

[23] Y. Q. Chang, D. B. Wang, X. H. Luo, X. Y. Xu, X. H. Chen, L. Li, C. P. Chen, R. M. Wang, J. Xu, D. P. Yu, Appl. Phys. Lett. Vol. 83, No. 19, 2003, pp. 2292-2294.

[24] L. Vayssieres, K. Keis, S. -E. Lindquist, and A. Hagfeldt, J. Phys. Chem. B Vol. 105, No. 17, 2001, pp. 3350-3352.

[25] L. Vayssieres, K. Keis, A. Hagfeldt, and S. -E. Lindquist, Chem. Mater. Vol. 13, No. 12, 2001, pp. 4395-4398.

[26] L. E. Greene, M. Law, J. Goldberger, F. Kim, J. C. Johnson, Y. F. Zhang, R. J. Saykally, and P. D. Yang, Angew. Chem. Int. Ed. Vol. 42, No. 26, 2003, pp. 3031-3034.

[27] B. Liu, and H. C. Zeng, J. Am. Chem. Soc. Vol. 125, No. 15, 2003, pp. 4430-4431.

[28] S. W. jung, S. J. An, G. C. Yi, C. U. Jung, S. I. Lee, S. Cho, Appl. Phys. Lett. Vol. 80, No. 24, 2002, pp 4561- 563.

[29] V. A. L. Roy, A. B. Djurisic, H. Liu, X. X. Zhang, Y. H. leung, M. H. Xie, J. Gao, H. F. Liu, C. Surya, Appl. Phys. Lett. Vol. 84, No. 5, 2004, pp 756-758.

[30] B. D. Yao, L. Feng, C. Cheng, M. M. T. Loy, N. Wang, Appl. Phys. Lett. Vol. 96, No. 22, 2010, pp. 223105 (1-3).

[31] D. Dingle, Physics Review Letters, Vol. 23, No. 11, 1969, pp. 579-581.

[32] B. Q. Cao, F. Q. Sun, W. P. Cai, Electrochem. Solid-State Letters. Vol. 8, No. 9, 2005, pp. 237-G240.

[33] Y. Li, G. W. Meng, L. D. Zhang, Appl. Phys. Lett. Vol. 76, No. 15, 2000, pp. 2011-2013.

[34] A. L. He, X. Q. Wang, Y. Q. Fan, and Y. P. Feng, J. Appl. Phys. Vol. 108, No. 8, 2010, pp. 084308(1-5). 